Revue internationale de l'économie sociale

Recma

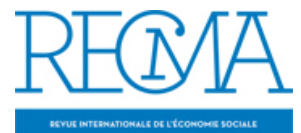

\title{
L’économie sociale et solidaire et le travail
}

\section{Gilles Caire}

Numéro 323, janvier 2012

L'ESS et le travail

Work in the social and solidarity economy

URI : https://id.erudit.org/iderudit/1018343ar

DOI : https://doi.org/10.7202/1018343ar

Aller au sommaire du numéro

Éditeur(s)

Association Recma

ISSN

1626-1682 (imprimé)

2261-2599 (numérique)

Découvrir la revue

Citer cet article

Caire, G. (2012). L'économie sociale et solidaire et le travail. Revue internationale de l'économie sociale, (323), 42-43.

https://doi.org/10.7202/1018343ar d'utilisation que vous pouvez consulter en ligne.

https://apropos.erudit.org/fr/usagers/politique-dutilisation/ 


\title{
L'ÉCONOMIE SOCIALE ET SOLIDAIRE ET LE TRAVAIL
}

\author{
par Gilles Caire*
}

\footnotetext{
* Maître de conférences, HDR de sciences économiques, Crief-université de Poitiers, coordinateur, avec Patrice Braconnier, des $\mathrm{Xl}^{\text {es }}$ rencontres du Riuess. Mél.: gilles.caire@univ-poitiers.fr.
}

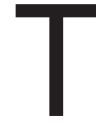
ravaille-t-on réellement autrement dans l'économie sociale et solidaire? Telle était la question sous-jacente des XI ${ }^{\text {es }}$ rencontres du Réseau inter-universitaire de l'économie sociale et solidaire (Riuess), qui se sont tenues à Poitiers en juin 2011 ${ }^{(1)}$.

\section{Réinterroger l'ESS sur ses conceptions et pratiques vis-à-vis du travail}

(1) Ces Xles rencontres ont bénéficié du soutien du conseil régional Poitou-Charentes, du conseil général de la Vienne, de la communauté d'agglomération Grand Poitiers, de l'université de Poitiers, de la Fondation Crédit coopératif, de la Caisse des dépôts, de la MGEN, de la Maif, de I'Usgeres, de Coop Atlantique et de l'ECF.
(2) L'intégralité des communications présentées à Poitiers - et lors des colloques précédents, à Luxembourg (2010), Roanne (2009) et Barcelone (2008) - sont accessibles sur le site www. riuess.org. Un ouvrage reprenant une sélection des textes des $\mathrm{Xl}^{\text {es }}$ rencontres est en préparation pour publication fin 2012.
Au cours de la seconde moitié du XIX ${ }^{e}$ siècle, l'économie sociale s'est largement construite autour de la "question sociale» et de la volonté des mouvements socialistes, ouvriers, chrétiens sociaux ou humanistes d'améliorer le sort des travailleurs et de contribuer à leur émancipation. Aujourd'hui encore, l'économie sociale revendique "un régime particulier d'appropriation, de distribution ou de répartition des gains " (Charte de l'économie sociale, Cnlamca, 1980), se veut "génératrice d'emplois de qualité comme d'une meilleure qualité de vie et propose un cadre adapté aux nouvelles formes d'entreprise et de travail " (déclaration de principes de la Conférence européenne permanente des coopératives, mutualités, associations et fondations, 2001). De son côté, durant les années 80, l'économie solidaire a émergé dans une situation d'exclusions durables du marché du travail et d'exploitation des petits producteurs, au Sud comme au Nord, par les grandes firmes capitalistes. Elle s'est proposé pour projet de "recréer un triangle vertueux entre l'emploi, la cohésion sociale et la démocratie participative" (Manifeste de l'économie solidaire, 2006) et de "créer etlou consolider des emplois en veillant à leur qualité, à leur pérennité et à leur professionnalisation" (France active, 2005).

La crise économique majeure actuelle provoque une profonde dégradation des conditions d'emploi et de travail: progression du chômage, précarisation des contrats, accroissement des inégalités de rémunération, absence de négociations collectives... Dans ce contexte, il a semblé opportun au comité de pilotage du Riuess de réinterroger l'économie sociale et solidaire sur ses conceptions et pratiques vis-à-vis du travail. Les quatre textes retenus dans ce dossier de la Recma témoignent, au-delà des champs disciplinaires différents de leurs auteurs, de la diversité des approches méthodologiques possibles et des principaux questionnements récurrents au sein des communications, des tables rondes et des débats pendant les $\mathrm{XI}^{\text {es }}$ rencontres ${ }^{(2)}$. 


\section{Des formes d'emploi sont-elles objectivement plus favorables en ESS?}

Se différencient-elles quantitativement et qualitativement des secteurs capitaliste et public, en matière de sécurité de l'emploi, de rémunérations, de formations, de carrières, de durée et de conditions du travail, de protection sociale, de conventions collectives, d'égalité homme-femme, de conciliation entre vie familiale et vie professionnelle? Lapproche statistique comparative menée par Franck Bailly, Karine Chapelle et Lionel Prouteau sur la région Pays de la Loire apporte des réponses rigoureuses et nuancées sur ces différentes dimensions.

\section{Un travail vécu de façon plus " enchantée " en ESS?}

Ressent-on un meilleur respect de l'humain, plus de liberté, de créativité et d'autonomie, des relations à la hiérarchie plus apaisées, une utilité sociale de l'activité porteuse de sens? L'article monographique sur la Croix-Rouge française de Monique Combes-Joret et Laëtitia Lethielleux est centré sur ces perceptions en interne des acteurs, en recueillant et en croisant les points de vue - là aussi très nuancés - des salariés, du bas et du haut de l'échelle hiérarchique, mais aussi des dirigeants élus et des bénévoles. Il témoigne également des nombreuses remises en cause, au cours du colloque de Poitiers, de la dichotomie salariat-travail et bénévoles-engagement militant.

\section{Un dialogue social plus facile au sein des structures de I'ESS?}

Qu'en est-il des relations collectives, de la participation des salariés, du rôle des délégués du personnel ou du comité d'entreprise, des postures syndicales et des pratiques des employeurs? En réponse à ces questions, Gilles Rivet dresse un portrait de terrain relativement défavorable de l'état de la démocratie sociale en ESS, en partie du fait de la faible taille des organisations concernées, mais aussi en raison de profondes incompréhensions, voire de méfiances historiques sur la place du salarié au sein de ces organisations tant du coté syndical qu'employeur.

\section{Le travail « métamorphosé » par l’ESS?}

Peut-elle constituer un espace spécifique de reconfiguration, voire de dépassement du salariat et proposer des formes de libération du travail en opposition aux logiques marchandes et monétaires, dans la continuité des courants utopistes du XIX siècle? Dans une approche de déconstruction de la science économique dominante, Eric Dacheux et Daniel Goujon proposent ainsi de concevoir l'économie solidaire comme la suppression nécessaire du salariat combinée à la mise en place du revenu d'existence. 